\title{
Change in climatic extremes over mainland China based on an integrated extreme climate index
}

\author{
G. $\operatorname{Ren}^{1, *}$, Y. Chen $^{1}$, X. K. Zou ${ }^{1}$, Y. Q. Zhou ${ }^{1,2}$, Y. Y. $\operatorname{Ren}^{1}$, Y. Jiang ${ }^{1}$, F. M. Ren ${ }^{1}$, \\ Q. Zhang ${ }^{1}$, X. L. Wang ${ }^{1}$, L. Zhang ${ }^{1}$ \\ ${ }^{1}$ Laboratory for Climate Studies, National Climate Center, China Meteorological Administration, Beijing 100081, PR China \\ ${ }^{2}$ Jinzhong Meteorological Bureau, Jinzhong 030600, PR China
}

\begin{abstract}
An Integrated Extreme Climatic Index (IECI) is defined for analyzing the overall trend of change in the frequencies of major extreme climatic events over mainland China. The index is composed of 7 individual extreme indicators, i.e. the country-averaged frequencies of high temperature, low temperature, intense precipitation, dust storm and strong wind events, meteorological drought area percentage, and number of land-falling tropical cyclones (TCs). Weights are assigned to the individual country-averaged extreme indices based on the mean economic losses and casualties induced by the extreme events in the last $5 \mathrm{yr}$. The IECI is then defined as the weighted sums of the standardized individual extreme climatic indices. During the past 54 yr (1956-2009), the IECI has shown no significant change in terms of linear trend, although inter-annual and inter-decadal variations are evident, with lower values and a decreasing trend occurring from the late 1950s to the early 1980s, and higher values and an increasing trend since the mid-1980s. In view of the individual extreme climatic indices, significant upward trends were detected for frequencies of high temperature events and the percentage of meteorological drought areas, and significant downward trends were found for frequencies of low temperature, dust storms, and strong wind events. The number of land-falling TCs is in an insignificant decline, and no significant trend was found for frequency of intense precipitation events. Our analysis revealed that the frequencies of major extreme climatic events with the potential to cause severe meteorological disasters in mainland China show more complicated changes during the period of accelerated climate warming.
\end{abstract}

KEY WORDS: Climate extremes - Climate impact · Integrated Extreme Climatic Index (IECI) · Meteorological disasters $\cdot$ Indices of extremes $\cdot$ Climate change $\cdot$ Mainland China

\section{INTRODUCTION}

It is important to understand whether or to what extent major extreme climate events over a large region like mainland China have changed in frequency and intensity during the past decades when global surface temperature underwent a significant increase. The frequency and intensity of extreme climate events have been expected to increase or decrease, and the associated meteorological disasters to be aggravated or lessened, against the back- ground of global warming. Studies on changing trends of global and regional observed extreme climate events in the recent past and projections of their possible changes in the future are critical for assessing the effects of extreme climate events on natural and human systems, and for forging adaptation measures to regional climate change.

Previous analyses have addressed the observed and projected trends in frequency and intensity of various individual extreme climate events. Both the frequencies and intensities of extreme intense pre- 
cipitation over mid- and high-latitude land regions of the Northern Hemisphere have increased in recent decades (Alexander et al. 2006, IPCC 2007), and the frequency of abnormally cold nights related to daily minimum temperature over most land regions has decreased significantly, whereas the frequency of abnormally warmer nights has significantly increased (Easterling et al. 2000, Frich et al. 2002, IPCC 2007, Ding \& Ren 2008, Choi et al. 2009). Droughts in subtropical areas across global land regions have become more intense and longer in duration (Dai et al. 2004), and an increase has been observed in intense tropical cyclone (TC) activities in the North Atlantic (IPCC 2007). Some studies have suggested that the higher frequency of extreme weather and climate events may have been the main factor for increased economic loss of meteorological disasters in many regions of the world (e.g. Anemüller et al. 2006), but others have shown that such increasing loss might not necessarily have been induced by a higher frequency of extreme weather and climate events (Kunkel et al. 1999, Changnon et al. 2000, Pielke 2007). Most studies have suggested that the frequency change of temperature-related abnormally cold (warm) nights (days) is attributable to anthropogenic greenhouse gas emissions, and the higher frequency of extreme intense precipitation events over land areas in mid- and higher latitudes of the Northern Hemisphere is a response to anthropogenic global warming (IPCC 2007, Zhang et al. 2007).

Previous studies have mostly focused on temporal change in individual extreme climate events or categories of such events, and there is a lack of comprehensive studies that address recent changes in multiple categories of extreme climate events for a particular region or country. To detect regional climate change and its effects, and to take governmental and public action in response to climate change, analysis of an overall change in both the frequencies and intensities of multiple extreme climate events in a region or country is required to capture any signals that reflect possible responses of a regional climate to anthropogenic external forcing, and to better understand integrated effects of the multiple extreme climate events in terms of their frequency and intensity changes. For example, governments and the public need to understand to what extent the extreme climate events causing serious economic losses and human casualties have increased or decreased in general against the background of global warming for the past half century. This question could be answered by analyzing and summarizing each of the current individual extreme climatic indices. How- ever, due to the wide variety and complexity of such indices, the change trends of the different index series vary largely from one to another, and it is difficult to show an overall change picture. Therefore, how to choose indicators with evident climatological and socio-economic significance from a wide range of complex extreme climate indices to establish a regional integrated extreme index, and how to analyze the temporal trends of the integrated index series in the past and future, become an issue that warrants further study.

Karl et al. (1996) first defined a Climate Extreme Index (CEI) for US mainland territories, which comprehensively takes into account extreme temperature and precipitation indicators, and they analyzed CEI variations over time. Hansen et al. (1998) proposed a climate change index which considers the indicators with practical application values, including heating degree day and frequency of intense precipitation events. Baettig et al. (2007) introduced another index that takes into account the number of the warmest, driest, and wettest years, and the number of years with abnormally warm summers and winters. The latter 2 indices not only address extreme climate, but also include descriptions of mean climatic variables; however, the indicators used in the 2 indices are incomplete, especially neglecting those extreme climate events related to low temperature.

The CEI consists of 5 individual indicators, i.e. monthly mean maximum and minimum temperature, extreme $1 \mathrm{~d}$ precipitation amount, numbers of precipitation days and no-precipitation days as well as the Palmer Drought Severity Index (PDSI), and the analysis is based on annual and seasonal averages (Karl et al. 1996). The absolute thresholds are used for extremely dry and wet conditions as well as for $1 \mathrm{~d}$ extreme precipitation, and the extreme events in other indicators are defined as significantly higher (or lower) than normal values (beyond the 90th or 10th percentile) in terms of occurrence frequency. The percentage areas (latitudinal and longitudinal grids) within the contiguous US, where extreme climate events in the 5 individual indicators occurred, are then calculated respectively and are arithmetically averaged. Each single indicator (e.g. monthly mean maximum temperature) is further broken down into 2 indices, i.e. abnormally high or low values. By analyzing the temporal variations of the CEI for the contiguous US, the linear trend was found to be insignificant for 1910-1994, but the decadal fluctuation was noticeable, and a rising trend was quite clear since the mid-1970s (Karl et al. 1996). 
Gleason et al. (2008) revised the CEI by increasing data sites for earlier years and by updating the dataset to 2006. Another major revision is that the extremely dry and wet thresholds $(-3$ to +3$)$ in the PDSI (values of -3 to +3 ) are changed into percentile values (upper and lower $10 \%$ ), and the $1 \mathrm{~d}$ extreme precipitation threshold is also changed from the absolute threshold of $50.8 \mathrm{~mm}$ to a percentile value (upper $10 \%$ ). The updated CEI series for the contiguous US shows a highly significant rising trend since 1994 and a significant rising trend for the period 1910-2006, suggesting that the frequency and intensity of extreme climate events related to temperature and precipitation are increasing over the contiguous US as a whole.

As there are different climatic conditions among regions or countries around the world, extreme climatic events differ in their variety and impacts. Although there is much similarity between China and the US in climatic conditions, meteorological disasters such as frequent summer rainstorms, typhoons, and dust storms that occur annually in China are not as severe in the US. The idea of constructing a CEI has a reference value for other regions or countries, but the selected indicators in the US CEI are not applicable elsewhere. In addition, the CEI also has other deficiencies even for the contiguous US. Local or regional events such as hurricanes and tornados are not described in the integrated index, for example, because only the percentages of total areas where a specific extreme climate event occurs are calculated, although the extremes are equally or even more important for the country. The CEI gives equal weights to the impacts of the 5 extreme climate events. However, the economic and social impacts of different extreme events actually vary from one region or country to another. Abnormal warmness related to winter minimum temperatures could cause much less damage to energy, transportation, and telecommunication sectors than abnormal coldness in the contiguous US, for example, and the impacts of extreme climate events related to maximum temperature could not be indifferently treated as those of severe droughts in mainland China.

Based on mainland China's specific situation of climate and weather disasters, and the severities of impact of various extreme climate events on the economy and on casualties, Ren et al. (2010) defined an integrated extreme climatic index and analyzed the variations of the index series for 1956-2008. Here we make a few minor revisions of the index, and update the dataset to 2009, to comprehensively analyze the temporal changes of the index and the individual extreme climate indicators of which the index is composed.

\section{DEFINITIONS AND METHODS}

\subsection{Definitions}

Communities and regions in the same country have different focuses on extreme climate events. People living in inland areas of northern China, which are generally not affected by typhoons, are deeply concerned about such extreme events as drought, dust storms, and strong wind, whereas people living in southern China are worried about typhoons, heavy rainfall and associated floods, and extreme high temperatures. From a national perspective, farmers are concerned about drought and flooding; urban dwellers are more affected by high and low temperatures, dust storms, and strong wind; governmental agencies usually pay more attention to the extreme events that may cause heavy casualties and economic losses; and climate change researchers are more interested in changes in extreme events related to temperature, as these are particularly important for detecting climate change. Therefore, how to select the extreme climate events that more evidently affect a region or a community should be considered first.

Mainly based on the severities of the economic and social effects of various extreme climate events, Ren et al. (2010) selected 7 extreme climatic indicators, which generally indicate the most frequently occurring weather and climate extremes in mainland China, to define an Integrated Extreme Climate Index (IECI). The 7 extreme indicators include the average number of high temperature days (Htd), average number of low temperature days (Ltd), average number of intense precipitation days (Ipd), meteorological drought area percentage (Dap), landing TC (typhoon) frequency (Tcf), average number of dust storm days (Dsd), and average number of strong wind days (Swd). These indicators are also used here for calculating the IECI. TCs are classified into 6 categories in China based on the maximum wind speeds of the cyclone centers: tropical depression (10.8$\left.17.1 \mathrm{~m} \mathrm{~s}^{-1}\right)$, tropical storm $\left(17.2-24.4 \mathrm{~m} \mathrm{~s}^{-1}\right)$, strong tropical storm (24.5-32.6 $\left.\mathrm{m} \mathrm{s}^{-1}\right)$, typhoon (32.7$\left.1.4 \mathrm{~m} \mathrm{~s}^{-1}\right)$, strong typhoon (41.5-50.9 $\mathrm{m} \mathrm{s}^{-1}$ ) and super typhoon (above $51.0 \mathrm{~m} \mathrm{~s}^{-1}$ ). Typhoon, strong typhoon and super typhoon are generally called typhoons. Heavy snow events have attracted increasing attention in recent years. However, heavy snowfall usually occurs locally in northern Xinjiang and the northern northeast, and intense precipitation events incorporate the influence of heavy snowfall to a certain extent. Therefore, heavy snow events were not used as an independent indicator in this study. 
The reason for excluding those indicators representing the intensity/magnitude of extreme climate events and the drought indices other than droughtaffected scope (area) is that the region-average frequency of extreme climate events has excellent correlations with their intensity/magnitude and area percentage. Both the country- and region-averaged number of extreme climate event days or frequencies can therefore well represent the corresponding intensities/magnitudes and affected scopes. For example, the station and regional average number of intense precipitation days has significant positive correlations with the intense precipitation amount (or intense precipitation intensity and number of stations [grids]) above the 95th percentile threshold. Fig. 1 shows the highly significant correlation between the number of intense precipitation days and intense precipitation amounts above the 95th percentile threshold for national climate reference stations and basic meteorological stations in mainland China. Among 560 stations calculated, only 8 stations had correlation coefficients $<0.70$, and all of the positive correlations are statistically significant at the 0.05 confidence level. Of course, the significant correlation between intense precipitation days and the intense precipitation amount does not necessarily mean that the 2 time series will display the same long-term trends, and there is a need to differentiate the effect of interannual variability and long-term trends of the indicator series on the calculation results. However, the correlation coefficients are generally dependent not only

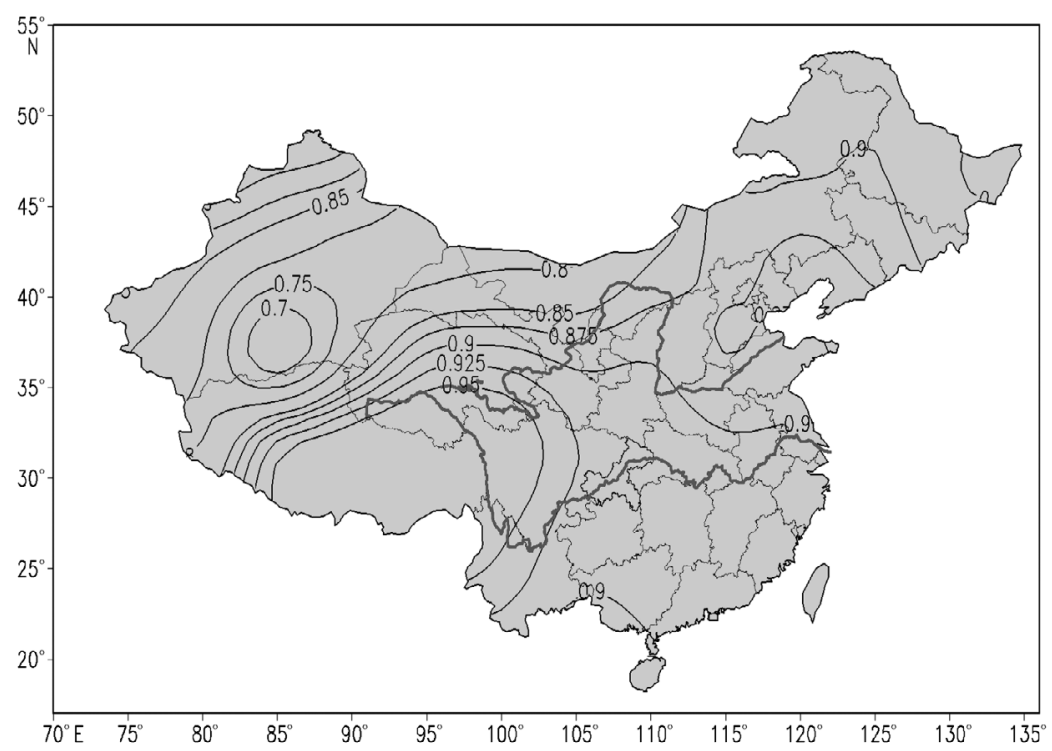

Fig 1. Correlation coefficients between intense precipitation days and intense precipitation amounts above the 95th percentile threshold in China. All of the correlations for the stations calculated are statistically significant at the 0.05 confidence level on the interannual variability, but also on the linear trends to a large extent. When the correlation coefficients are positive (negative) and statistically highly significant, the 2 time series are more likely to display similar long-term trends. Therefore, only Ipd is used in this paper to represent the extreme intense precipitation event and its change with time.

The 7 individual extreme climate indicators selected represent the commonly occurring weather and climatic phenomena that often cause meteorological disasters in mainland China, leading to serious losses of lives and property. High temperatures in summer are related to heat waves, causing water and electricity shortages, heat strokes, and even deaths. Low temperature can bring about frost, icing, and cold waves, causing heavy losses in agricultural production, transportation, telecommunications, and power overloads. Intense precipitation events often trigger flooding, which is a major factor for huge economic losses and casualties in eastern China. Drought mainly has adverse impacts on agriculture and water supply. Heavy rainfall and strong winds induced by TCs (typhoons) may give rise to severe floods and wind hazards in coastal areas. Dust storms can seriously affect ecological systems, environment, and human health in addition to damage to agricultural production in northern provinces. Strong wind events unrelated to dust storms and TCs can also cause serious damage at local scales.

In addition, extreme weather and climate events also include local severe convective phenomena such as thunderstorms, tornadoes, and hail in mainland China, although complete observational records are lacking. The impacts of these small-scale weather phenomena are local and instantaneous in nature, and partially incorporated in the indices of intense precipitation, strong winds, and TCs; therefore, they have not been treated separately in the IECI. Although snowstorminduced disasters in northern China are important events, there has been little research of extreme intense snowfall to date. Snowstorms are also closely related to winter low temperatures and intense precipitation, and their impacts have been partially incorporated in the relevant indices. Similarly, snowstorms are not calculated in the IECI as an independent indicator.

Weather and climate disasters induced by the individual extreme climate events 
vary largely in terms of severity, and they should be differentially treated in the IECI. Historically and in modern times, rainstorm-induced floods are a major disaster, causing the heaviest direct economic losses and casualties in mainland China. For the past half century, floods have annually affected $8.67 \times 10^{6} \mathrm{hm}^{2}$ of farmlands on average, with a direct economic loss accounting for more than one-third of total losses caused by natural disasters (Gao 1997). On average, a major flood claiming a death toll of more than 1000 occurs every 3 yr (Gao 1997). Therefore, the highest weight in the IECI should be given to the index of intense precipitation events. Drought is the second most damaging meteorological disaster in China after floods, affecting $2.00 \times 10^{7} \mathrm{hm}^{2}$ of land on average every year, and leading to crop yield reduction that accounts for more than $50 \%$ of the total caused by natural disasters (Gao 1997). A severe drought puts urban water supplies under stress and causes water shortages in rural areas, leading to desertification, forest fires, and dust storms, which negatively affect economy and society. Heavy rains, storm surges, and strong winds associated with TCs pose huge threats to coastal zones. Although the death toll continues to decline, direct economic losses from TCs have risen significantly worldwide, probably due to the increasing assets located in exposed coastal zones in recent years (CMA 2007, Pielke 2007). TCs are therefore extreme weather events that have received increasing attention from all interest groups. Meteorological disasters induced by extreme low temperature are also very severe. Cold waves hit eastern mainland China in spring, autumn, and winter; low temperatures damage agriculture of northeast China in summer; and cold spring or freezing rain in southern China sometimes cause heavy losses to the local economy. In addition, events like extreme high temperatures, dust storms, and strong winds along with associated disasters have become a focus of increasing attention. However, since they generally cause fewer direct economic losses and deaths, they could be given relatively lower weights in the IECI.

Table 1 lists direct annual mean economic losses and deaths caused by the disasters associated with extreme climate events for China for the period 2004-2008. Direct annual mean economic losses from low temperature disasters include effects of low temperature, icing, and snowfall. According to the direct economic losses and the number of deaths available at present, flood ranks first in annual average, followed by typhoons or TCs, drought, and low temperature/icing (snowing) disasters. The economic losses of drought only include those due to reduced agricultural production, and the damages to urban and rural water supplies, energy consumption, and forest fires caused by drought are not calculated. Therefore, the economic loss figures given here are conservative and incomplete, especially for drought disasters. It is estimated that the actual impacts of drought on varied sectors should outweigh those of typhoons or TCs (Gao 1997, CMA 2007).

The relative importance of the extreme climate indicators is judged based on the effects of the associated meteorological disasters, especially in terms of direct economic losses and number of deaths. Each of the extreme climate indicators is given an appropriate weight coefficient (shown from highest to lowest in Table 1). The 2 indicators Dsd and Swd are assigned the same weight $(0.05)$ becasue they similarly cause only relatively modest to slight losses. The above weight assignment also considers the linkage/overlap between the individual extreme climate indicators, e.g. between Swd and either Tcf or Dsd, and between Tcf and Ipd, to avoid overemphasizing any single indicator. The lower weights for Swd and the Dsd are due to this consideration.

The above assignment of weights is tentative, and improvements can be made when the data for economic losses and fatalities related to extreme weather events in China become available in the future. How-

Table 1. Major meteorological disasters, the associated extreme climate events, and the annual mean losses in mainland China for the 5 yr period of 2004-2009. (-): not available. 1 Yuan RMB $\approx$ US\$ 0.15. Data from 'Yearbooks on damage caused by natural disasters' published by the Chinese Ministry of Civil Affairs

\begin{tabular}{|llccc|}
\hline Disaster & Indicator (abbreviation) & Economic loss $\left(10^{6}\right.$ Yuan RMB) & Deaths & Weight coefficient \\
\hline Flood & Intense precipitation days (Ipd) & 6.503 & 966 & 0.30 \\
Drought & Drought area percentage (Dap) & 4.723 & - & 0.25 \\
Typhoon & Landing TC frequency (Tcf) & 4.907 & 487 & 0.20 \\
High temperature & High temperature days (Htd) & - & - & 0.07 \\
Low temperature & Low temperature days (Ltd) & 4.239 & 61 & 0.08 \\
Dust storm & Dust storm days (Dsd) & - & - & 0.05 \\
Strong wind & Strong wind days (Swd) & - & - & 0.05 \\
\hline
\end{tabular}


ever, the ranking of the relative importance of the extreme events would be basically stable.

Daily observational data and percentile thresholds are used to obtain the individual extreme climate indices related to temperature and precipitation (Table 2). High-temperature days thus are defined as the annual number of days with daily maximum temperature higher than the 90th percentile value of the climate reference period (1971-2000), which mainly reflects the frequency of high-temperature events in daytime; low-temperature days refers to the annual number of days with a daily minimum temperature lower than the 10th percentile value, which reflects the frequency of low-temperature events at nighttime. Intense precipitation days refers to the annual number of days with daily $(24 \mathrm{~h})$ precipitation more than the 95th percentile value, which reflects the frequency of relatively intense precipitation events. The method by Zhang \& Yang (2004) was used to obtain the percentile thresholds for calculating the frequency indices (also refer to Alexander et al. 2006).

There are disadvantages with the percentile approach for defining extreme climate indicators. For a region that experiences only mild summers, for example, a day with the percentile high temperature record might not be associated with any negative consequences. An arid site might experience a disaster according to this definition, even though the daily total rainfall might be very low. However, the percentile procedure has advantages of region-toregion comparability and nationwide applicability. If a region-specific absolute threshold is applied, some stations and areas will not be included. For example, almost half of the area of the country will be missed when the indicator 'rainstorm' (defined as $24 \mathrm{~h}$ precipitation above $50 \mathrm{~mm}$ ) is used, because it merely occurs in the monsoon region of the southeast. This would be improper because an event of 20 to $49 \mathrm{~mm}$ of precipitation within $24 \mathrm{~h}$ in arid and semi-arid areas will cause severe problems for local communities. Similarly, people on the Tibetan Plateau will be negatively affected by a maximum temperature record of 25 to $30^{\circ} \mathrm{C}$, which will be felt by people of Shanghai as comfortable in the summertime. Human communities have usually adapted to local climate conditions; to a certain extent, they have their own 'normal' climate, and any significant departure from 'normal' will cause disorder or even disasters.

However, the percentile procedure is not used for strong wind frequency. Instead, it is defined as the number of annual days with instantaneous wind speed at any time of day greater than $17 \mathrm{~m} \mathrm{~s}^{-1}$ (equal to force 8 on the Beaufort scale, or 'gale'), which can indicate the frequency of strong wind events at a station. The instantaneous wind speed here is actually the average value of wind speed records of any $3 \mathrm{~s}$ when wind speed is continuously greater than $17 \mathrm{~m} \mathrm{~s}^{-1}$ in a day.

Drought area percentage is the ratio of meteorological drought areas (or grids) to the overall observational region (or grids). For meteorological drought, an index (Composite Index or CI) recommended in the national standard (Zhang et al. 2006) is adopted. The drought index combines potential evapotranspiration calculated using the Thornthwaite method (Zhang et al. 2006) with the Standardized Precipitation Index (SPI) over the last 30 and $90 \mathrm{~d}$. CI is obtained with the following equation:

$$
\mathrm{CI}=a Z_{30}+b Z_{90}+c M_{30}
$$

where $Z_{30}$ and $Z_{90}$ are the SPI for the last 30 and $90 \mathrm{~d}$, respectively; $M_{30}$ is a relative wetness index for the last $30 \mathrm{~d}$ obtained by calculating the ratios of the precipitation-evapotranspiration difference to the

Table 2. Definitions of individual indicators of extreme climate events

\begin{tabular}{|c|c|c|c|}
\hline No & Code & Indicator & Definition \\
\hline 1 & Htd & High temperature days & $\begin{array}{l}\text { Days with daily maximum temperature }>\text { the } 90 \text { th percentile value of the } \\
\text { period 1971-2000 }\end{array}$ \\
\hline 2 & Ltd & Low temperature days & $\begin{array}{l}\text { Days with daily minimum temperature }<\text { the } 10 \text { th percentile value of the } \\
\text { period 1971-2000 }\end{array}$ \\
\hline 3 & Ipd & Intense precipitation days & $\begin{array}{l}\text { Days with daily precipitation amount }>\text { the } 95 \text { th percentile value of the } \\
\text { period 1971-2000 }\end{array}$ \\
\hline 4 & Dap & Drought area percentage & $\begin{array}{l}\text { Percentage of areas (or grids) with meteorological droughts to overall } \\
\text { observational region (or grids) }\end{array}$ \\
\hline 5 & Tcf & $\begin{array}{l}\text { Tropical cyclone (TC) } \\
\text { (typhoon) frequency }\end{array}$ & Annual number of TCs (typhoons) landing in coastal areas of mainland China \\
\hline 6 & Dsd & Dust storm days & $\begin{array}{l}\text { Average number of dust storm days within grid points with observational } \\
\text { records in a year }\end{array}$ \\
\hline 7 & Swd & Strong wind days & Days with instantaneous ( $3 \mathrm{~s}$ ) mean wind speed $>17 \mathrm{~m} \mathrm{~s}^{-1}$ \\
\hline
\end{tabular}


evapotranspiration for the last $30 \mathrm{~d}$; $a$ and $b$ are coefficients which are respectively the proportions of the averages to minima of $Z_{30}$ and $Z_{90}$ time series when $\mathrm{CI}>-0.6 ; C$ is a coefficient that is obtained by calculating the ratios of the averages to minima of $M_{30}$ time series when $\mathrm{CI}>-0.6$.

Zhang et al. (2006) and Zou et al. (2010) define meteorological drought as $\mathrm{CI} \leq-0.6$. Among the individual indicators, only meteorological drought is described in area percentage, as previous work mostly focused on the long-term change in meteorological drought area percentage. Nevertheless, if the country-averaged number of meteorological drought days in a year is used, the analysis results of temporal change should be very similar (Zou et al. 2010).

TC frequency refers to the number of TCs (typhoons) making landfall on the coastal areas of mainland China (occurrences mainly in summer and autumn). Dust storm days refers to the number of dust storm events (days) averaged by grid points with observed records of dust storms nationwide. Dust storms are formed when a strong wind blows up loose sand and dust from a dry land surface, resulting in a visibility less than $10 \mathrm{~km}$. They mainly occur in the spring in most areas of northern China. The country-averaged frequency of dust storm events is obtained by area-weighted averaging of the dust storm days within grid points with observational records within a year.

\subsection{Data and calculations}

The IECI is the sum of the above 7 individual extreme climate indicators:

$$
\text { IECI }=\Sigma \delta i E i(i=1,2,3, \ldots 7)
$$

where $\delta$ is the weight coefficient, and $E$ is the standardized value of individual extreme climate indicators.

The weights are assigned to the extreme climate indicators (Table 1), so that

$$
\begin{aligned}
\mathrm{IECI}= & 0.07 \mathrm{Htd}+0.08 \mathrm{Ltd}+0.3 \mathrm{Ipd}+0.25 \mathrm{Dap} \\
& +0.2 \mathrm{Tcf}+0.05 \mathrm{Dsd}+0.05 \mathrm{Swd}
\end{aligned}
$$

The data used are the observations from national reference climate stations and basic meteorological stations (up to 740 stations) during 1956-2009. Data for years prior to 1956 are incomplete for most of the stations, and previous research in mainland China has generally used observational records beginning in 1955 or 1956, making our results easier to compare. All meteorological data were provided by the
National Meteorological Information Center (NMIC), China Meteorological Administration (CMA). The surface air temperature data are the daily maximum/minimum temperatures. The data have been quality controlled and homogeneity adjusted by the researchers from the NMIC/CMA. The homogeneity adjustment of the temperature data is an advantage over the previous analysis by Ren et al. (2010). However, the daily maximum/minimum temperature data have not been urbanization-bias corrected. Although the daily precipitation data have been quality controlled, they have not been adjusted for inhomogeneities due to site relocation and instrument replacements. The precipitation data have not been adjusted for wind-induced 'under-catch' bias. The CI series is based on daily precipitation and daily mean temperature data (Zou et al. 2010). The wind speed data of the 740 stations have been quality controlled and corrected for inhomogeneities due to instrument replacement around 1970, but corrections for possible discontinuities due to the transition from manual to automatic observations after 2000 have not yet been conducted (Jiang et al. 2010). The effect of station relocation and instrument replacement on the landing TC records and the number of dust storm days is thought to be insignificant.

Statistics and analysis of the IECI series can be made on a monthly, seasonal, and annual basis, and can also be made on a local, regional, or national basis, but in this paper, the focus is the annual analysis of the country as a whole. For the extreme climate indicators with thresholds determined by percentile thresholds, we first calculated the annual series of indicators of individual stations across the country based on the methods by Zhang \& Yang (2004) and Alexander et al. (2006), and then obtained the average annual series for latitude/longitude grids of $2^{\circ} \times$ $2^{\circ}$ or $2.5^{\circ} \times 2.5^{\circ}$ by simply averaging all of the site values within the grids, and finally came up with a country-averaged annual series of the indicators by areaweighted averaging of all grid values. The weight coefficients are the cosine values of the mid-latitudes of the grids (Jones \& Hulme 1996). The national Dap was calculated using the method developed by Zou et al. (2010). The time series of area-averaged Dsd across the country was obtained by applying the method by Zhang \& Ren (2003). The country-averaged time series of the individual indicators were standardized (anomalies/mean square deviation) to obtain standardized extreme climate indicator series. The IECI was then calculated by summing the differentiated weighted standardized series of the individual indicators (Eq. 3). 
The IECI value is between -1.0 and 1.0. The larger the value of a given year is, the higher the frequency and intensity of the major extreme climate events and their effects in the country will be, and vice versa. The IECI is not a simple average of the individual indicators, but the yearly sum of the standardized values of the individual indicators. When all extreme climate indicators increase (decrease), the IECI will rapidly respond accordingly; but when some indicators increase while others decrease, the IECI will show relatively less significant change. A certain anti-phase linkage exists between the Dap and the Ipd, and between the Htd and the Ltd. As the Dap (Htd) increases (decrease), the Ipd (Ltd) will probably decrease (increase), and the 2 indicators offset each other to a certain extent, weakening their contribution to the standardized anomalies and trends of the IECI. This is justifiable from the perspective of their effects, however, because when the losses caused by drought in dry years are abnormally high, the losses due to extreme intense precipitation are more likely to be low. Hence the overall or net economic losses from droughts and floods in those years are still close to 'normal.'

The IECI can also be calculated on a seasonal basis. As extreme climate events leading to severe meteorological disasters mostly occur in summer, however, the IECI values for summer would usually be higher than those for winter. The IECI value would also vary significantly from region to region. Generally speaking, the IECI would differ from one region to another in the same season or from one season to another in the same region if we also calculate and analyze it on the seasonal and regional basis. In this paper, we only analyzed the temporal variation of the country-averaged annual mean individual extreme climate indicators and IECI series for the period 1956-2009. The significance of the linear trends of the individual extreme climate indicators and IECI series is judged using a $t$-test, and when $p<0.05(p<0.01)$, the trend is considered statistically significant (very or highly significant).

\section{CHANGE IN INDIVIDUAL EXTREME CLIMATE INDICATORS AND THE IECI}

\subsection{Individual indicators}

Figs. 2-4 show variations of the standardized individual extreme climate indicators during 1956-2009. Statistically highly significant linear trends can be seen for the country-averaged extreme temperature indices Htd and Ltd, which respectively have undergone increasing and decreasing trends over the last 54 yr (Fig. 2). The decrease of Ltd is much earlier and more significant than the increase of Htd. The continuous decline of Ltd began in the late 1960s, while the most obvious rise of Htd occurred only after the mid-1990s. The standardized values of Htd and Ltd have remained abnormally high and low, respectively, after 1998.

Fig. 3 illustrates variations of the standardized Ipd and Dap over 1956-2009. The 2 indicators show very similar increasing, albeit not significant, trends. An out-of-phase inter-annual variation of the 2 indices is obvious, however, indicating that when Ipd is larger (smaller) than normal, Dap will decrease (increase) in the year. The correlation coefficient between the 2 indicators is -0.46 , which is statistically significant. This is understandable, because when the intense precipitation frequency goes up (down) in the country as a whole, the national average total precipitation will generally increase (decrease), and the extent of drought-stricken areas will correspondently decrease (increase). It is also important to note that, as an indicator of the meteorological drought extent, Dap shows an increasing trend mainly due to the rising evapotranspiration calculated by using the Thornthwaite method, which to a large extent depends on surface air temperature (Zou et al. 2010).

Temporal variations in Tcf, Dsd, and Swd are shown in Fig. 4. A slight drop in Tcf can be seen, but the negative linear trend is insignificant at the 0.05 confidence level. After 2000, landing TCs are more often above the average level, leading to a reversal of the downward trend up to the late 1990s. Long-term decreasing trends can also be seen for Dsd and Swd, and the linear trends are statistically highly significant. The good relationship between Dsd and Swd is to be expected because strong wind events are usu-

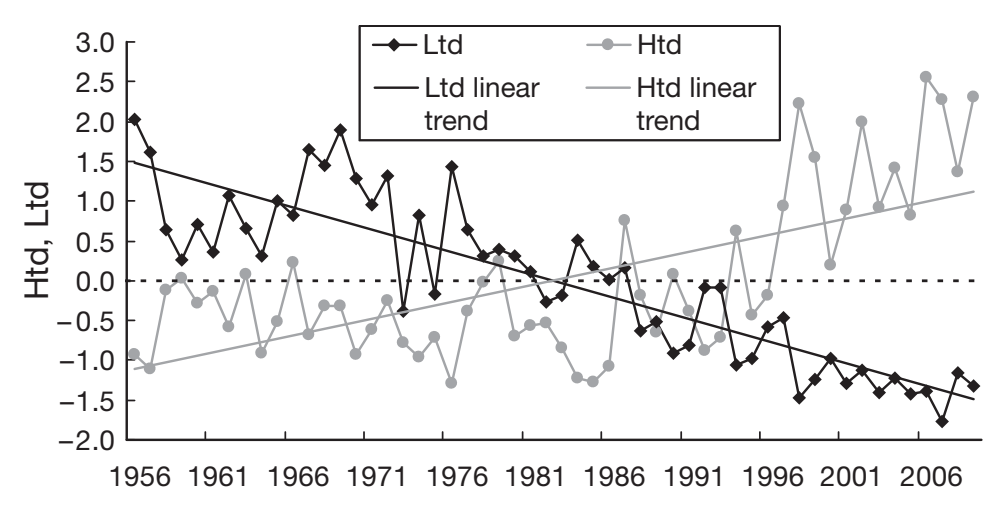

Fig. 2. Changes in country-averaged annual standardized extreme high temperature days (Htd) and low temperature days (Ltd) during 19562009. Horizontal dashed line: 0-value 


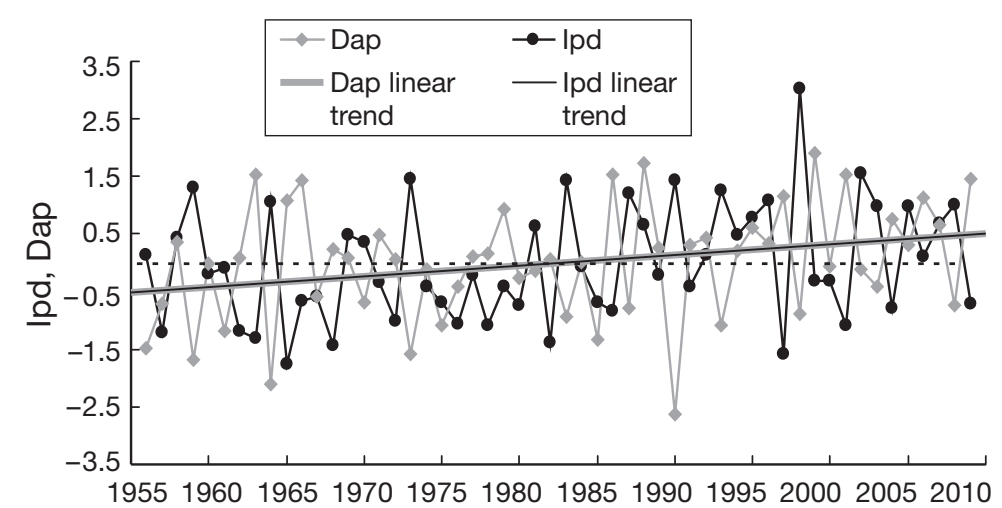

Fig. 3. As in Fig. 2, but for intense precipitation days (Ipd) and drought area percentage (Dap)

ally accompanied by dust storms in northern China. However, the divergences of Dsd and Swd at the 2 ends of the time series are also notable. The reason for the divergence in the late 1950s needs to be investigated, but it may have been caused by changes in the instrumentation used for wind speed observation. The more rapid decrease in Swd in the last $4 \mathrm{yr}$ might have been induced by the swiftly deteriorating observational settings for wind speed and/or by the nation-wide use of automated weather stations (AWS).

It is clear that a few of the individual extreme indicators, including Htd, Ipd, and Dap, are on the rise. The increasing trend in Htd passed the significance test at the 0.05 confidence level, but the trends of the other 2 indicators failed, indicating that the frequencies of high temperature events, intense precipitation events, and meteorological drought events increased over the time period analyzed, but only the frequency of high temperature events increased significantly. On the other hand, Ltd, Dsd, and Swd decreased, with all of the decreases passing the significance test, indicating that the frequencies of the cold (cool) events and wind speed-related extreme

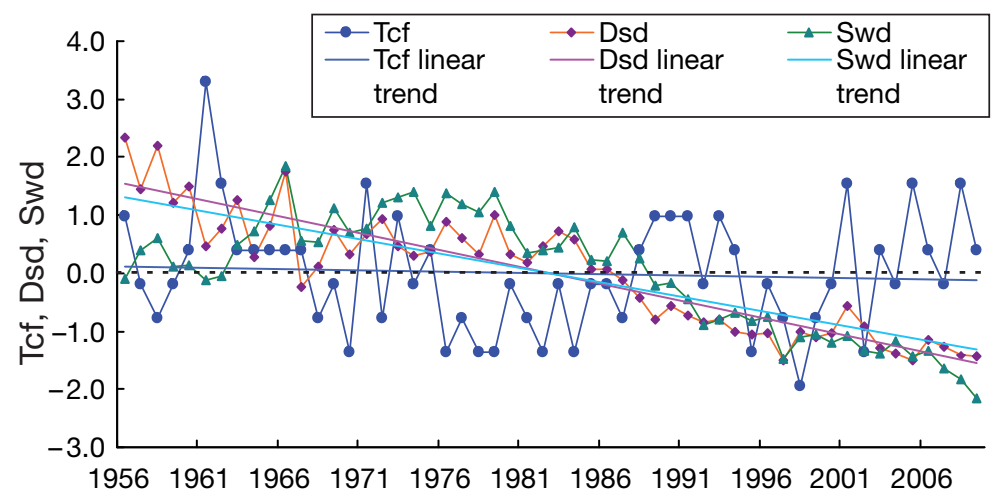

Fig. 4. As in Fig. 2, but for landing tropical cyclone frequency (Tcf), dust storm days (Dsd), and strong wind days (Swd) events experienced a significant decline. Tcf showed an insignificant decrease.

The variation characteristics of the individual extreme temperature indicators are generally consistent with previous studies for mainland China or East Asia (e.g. Zhai et al. 1999, Gong \& Han 2004, Wang et al. 2005, Qian et al. 2007, Ding \& Ren 2008, Choi et al. 2009, Zhou \& Ren 2010). The criteria for defining abnormally warm days and cold nights in the previous studies are similar to those used for high and low temperature indicators in this paper. Almost all previous studies have suggested a significant upward trend in warm days and a highly significant downward trend in cold nights in the country as a whole, in spite of the fact that a difference exists in the magnitude and spatial characteristics of the linear trends among the studies due to the varied data sets used and the time periods analyzed (Yan et al. 2002, Zhai \& Pan 2003, Qian et al. 2007, Ding \& Ren 2008, Zhou \& Ren 2010).

Urbanization effects on daily maximum and minimum temperature records (Ren et al. 2005, 2008, Zhou \& Ren 2010), apart from the possible effect of the increased atmospheric greenhouse gases (IPCC 2007, Ding \& Ren 2008), can partly explain the longterm trend of the Ltd series, and to a lesser extent that of the Htd series. However, the causes for the more rapid change since 1998 need to be investigated in the future, although it might have been associated with the instrument change from manual stations to AWS after 2000, in addition to the effect of accelerated urbanization on temperature records.

Country-averaged Ipd showed no significant increase, which is also broadly in line with the conclusions of previous studies on extreme precipitation (Zhai et al. 2005, Qian et al. 2007, Ding \& Ren 2008).

The time series of the meteorological Dap updated to 2008 showed a significant increasing trend, marginally passing the significance test at the 0.05 confidence level (Zou et al. 2010). Changes in Tcf, Dsd, and Swd reported here are also consistent with the conclusions from other studies (Zhang \& Ren 2003, Zhou \& Zhang 2003, Li et al. 2004, Fan et al. 2005, Wang \& Zhang 2006, Jiang et al. 2010).

Therefore, the time series for the individual extreme climate indicators obtained in this paper are representative for describing the temporal variations, in particular the long-term trends, of the major extreme cli- 
mate events in mainland China, and they can be confidently used for further composing the IECI series.

\subsection{IECI}

Using the methods described in Section 2.2 , the IECI series for mainland China was derived. Fig. 5 shows variation in the IECI series during 1956-2009. There is no significant long-term increasing or decreasing trend in the IECI series for the entire period analyzed. This indicates that, although the

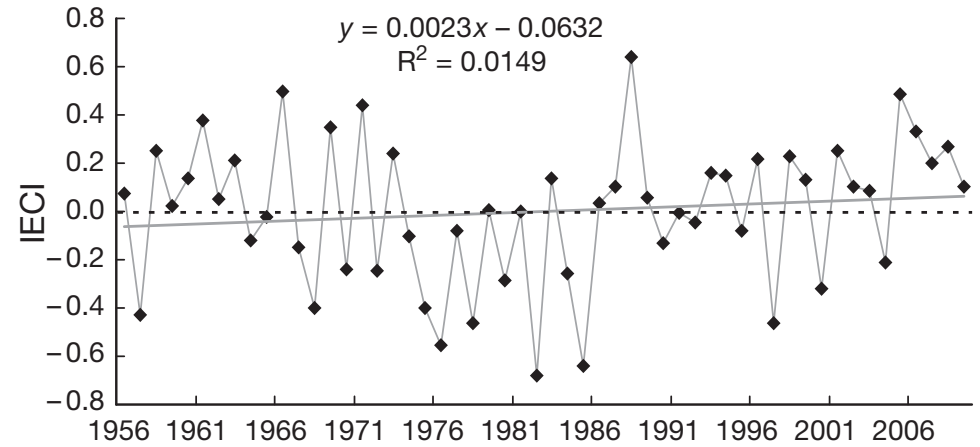

Fig. 5. Variation in the country-averaged Integrated Extreme Climate Index (IECI) over the period 1956-2009. Curved line: yearly IECI values; horizontal dashed line: 0-value; solid straight line: linear trend global and regional surface mean temperature significantly increased over the past $54 \mathrm{yr}$, the frequencies and intensities of major influential extreme climate events in mainland China as a whole have not undergone a significant rise as expected. This feature is illustrated and discussed by Ren et al. (2010). If equal weights are assigned to the 7 individual extreme climate indicators, which is thought to be unreasonable in view of the varied impacts of the extreme events on the economy and society of the country, a significant decrease in the IECI series will be obtained. The reasons for the less significant trend of the IECI series include that there are more individual extreme indicator time series showing significant downward trends, as illustrated in Section 3.1.

However, the IECI series shows marked interannual and decadal to multi-decadal variability. From the late 1950s to the early 1980s, for example, it has an evident decline, with positive values in most years to the early 1970 s, indicating that there are relatively more extreme weather and climate events, but they tend to decline toward the early 1980s. After the mid1980s, the IECI values increase and are mostly positive in the time period after 1990. The 1980s are unique because this decade witnessed the largest interannual fluctuations for the whole time period analyzed, with the lowest value in 1982 and the highest value in 1988, and the second lowest value appearing in 1985. Since the late 1990s, the inter-annual variability of the IECI series has been relatively small.

The decadal to multi-decadal variations of the IECI series indicate that major extreme climate events with significant impacts on the country are more frequent from the late 1950s to the early 1970s, and they are the most infrequent from the mid-1970s to the mid-1980s. After the mid-1980s, the major influential extreme climate events in mainland China tend to be more frequent once again. The Ipd, Dap, and Tcf with higher weights are the main drivers for the inter- annual and decadal variations of the IECI series. For example, the IECI shows an upward trend after the mid-1980s, particularly evident after the mid-1990s, and this is mainly due to the increase of Ipd, Dap, and Tcf, and also due to the substantial increase of the Htd. Although Ltd, Swd, and Dsd significantly decrease, their weights assigned are generally small, and they contribute little to the overall trend of the IECI series in the last $20 \mathrm{yr}$.

The 5 lowest and highest IECI values in 1956-2009 are listed in Table 3. Among the 5 yr with the lowest IECI values, 1982, 1997, 1978, and 1976 rank the 4th, 2nd, 9th, and 10th lowest, respectively, in terms of Ipd, and therefore, they are among the years with the least extreme precipitation in the entire period; 1976, 1978, and 1982 rank 3rd, 4th, and 6th from the bottom, respectively, in the time series of Tcf, and 1985 ranks the 6th lowest in the Dap time series. Among the $5 \mathrm{yr}$ with highest IECI values, 1961, 2005, and $1971 \mathrm{rank}$ top 1st, 3rd, and 5th in Tcf, and 1988 and 1966 register as the 2 nd and 7 th highest values of Dap.

It is therefore obvious that the abnormally high values of the IECI series are usually associated with more frequent land-falling TCs and a more extensive meteorological drought area, and the abnormally low values generally result from fewer frequencies of intense precipitation events and land-falling TCs. These ex-

Table 3. Lowest and highest IECI values (parentheses) for mainland China for the period 1956-2009

\begin{tabular}{|lll|}
\hline Rank & Record low & Record high \\
\hline 1 & $1982(-0.68)$ & $1988(0.64)$ \\
2 & $1985(-0.64)$ & $1966(0.50)$ \\
3 & $1976(-0.55)$ & $2005(0.48)$ \\
4 & $1978(-0.46)$ & $1971(0.44)$ \\
5 & $1997(-0.46)$ & $1961(0.38)$ \\
\hline
\end{tabular}


treme indicators possess larger inter-annual variability and relatively high weights, and they play more important roles in the variation of the IECI series.

It is worth noting that interactions exist to some extent between the different individual indicators, with the increase of one extreme climate indicator depending on the decrease of another, and vice versa. An example is the significant negative correlation between Ipd and Dap, and between Htd and Ltd. Therefore, in the years with severe drought or frequent heavy precipitation events, the IECI values would not be necessarily high due to the offset effect. For example, the most severe floods in the past 54 yr occurred in 1998 in the Yangtze River and the Songhuajiang River of northeast China, but the IECI value of 1998 is not as high due to the extremely small meteorological drought percentage and the lowest number of landing TCs, despite the country-averaged intense precipitation frequency peak in that year.

\section{DISCUSSION AND CONCLUSIONS}

Based on 7 individual extreme climate indicators which have larger effects on the socio-economy of mainland China, we defined an IECI.

The annual Htd, Ipd, and Dap increased in the period analyzed. The increasing trend in Hpd is statistically significant, while the trends of the Ipd and Dap are not. On the other hand, the annual Ltd, Dsd, and Swd all showed a significant decreasing trend during 1956-2009. The frequency of land-falling TCs (typhoons) shows an insignificant decrease. The IECI series shows no significant long-term trend during 19562009, although marked inter-annual and decadal to multi-decadal variability can be detected. An evident decline occurs from the late 1950s to the early 1980s, and a general increase occurs after the mid-1980s.

In the past 5 decades, mainland China, like the rest of the world, has witnessed significant climate warming. Most researchers agree that the observed climate warming in this period is very likely caused by the increase of greenhouse gas concentrations in the atmosphere (IPCC 2007). Previous studies have also shown that the extreme weather and climate events have increased in frequency and intensity in the past half a century against the background of global climate warming (e.g. IPCC 2007). Our analysis shows that in the context of significant global warming, the frequencies of the most harmful extreme climate events in mainland China have either significantly decreased or only marginally significantly increased, leading to an insignificant long-term trend in the
IECI series as defined in this paper during the past $54 \mathrm{yr}$.

Uncertainties in the results reported here are mainly related to the data. The calculation results of the individual extreme climate indicators are, to some extent, influenced by biases of surface air temperature records, including the possible effect of switching from manual stations to AWS observations on daily maximum and minimum temperature records after 2000 (Wang et al. 2007), and the significant effect of urbanization on surface air temperature trends especially on the minimum temperature trends in mainland China (Ren et al. 2005, 2008). These might have led to an overestimation of the trends in Htd and Ltd. We also found that the tremendous drop in the annual mean surface wind speed in north China has been mostly caused by urbanization and changes in microenvironments of observation grounds (Liu et al. 2009), implying that the country-averaged trends in Swd shown in Fig. 4 have been significantly overestimated.

In addition, the weights assigned to the individual extreme climate indicators could be better estimated in the future when the data of direct economic losses and deaths induced by the meteorological disasters are available. We used the $5 \mathrm{yr}$ average losses of meteorological disasters induced by major extreme climatic events in mainland China as a reference for determining the indicator weights. The losses from each of the disasters will change if we choose different time periods, and the statistical figures are also incomplete for certain types of disasters, including economic losses caused by dust storms and high temperature events, and deaths resulting from high and low temperature events. However, the relative importance of meteorological disasters for the country as given in this paper is generally supported by historical records from past decades (Wen \& Ding 2008) and by the common perception of the public (Gao 1997, Wen \& Ding 2008).

It would also be interesting to consider region- and season-specific IECI definitions and analyses. Mainland China covers a relatively large territory with diverse climatic and geographical conditions, and seasonal differences in eastern China are obviously due to the influence of the Asian monsoon. There is a necessity to further analyze changes in the IECI series for different climatic regions and for different seasons of a certain region.

Acknowledgements. This study was financially supported by the Ministry of Science and Technology of China (2007BAC29B02 and 2007BAC03A01). We appreciate the constructive comments and suggestions made by the 3 anonymous reviewers. 


\section{LITERATURE CITED}

Alexander LV, Zhang X, Peterson TC, Caesar J and others (2006) Global observed changes in daily climate extremes of temperature and precipitation. J Geophys Res 111:D05109 doi:10.1029/2005JD006290

Anemüller S, Monreal S, Bals C (2006) Global climate risk index 2006: weather-related loss events and their impacts on countries in 2004 and in a long-term comparison. Germanwatch, Bonn

Baettig MB, Wild M, Imboden DM (2007) A climate change index: where climate change may be most prominent in the 21st century. Geophys Res Lett 34:L01705 doi: 10.1029/2006GL028159

> Changnon SD, Pielke RA Jr, Changnon D, Sylves RT, Pulwarty R (2000) Human factors explain the increased losses from weather and climate extremes. Bull Am Meteorol Soc 81:437-442

Choi G, Collins D, Ren G, Trewin B and others (2009) Changes in means and extreme events of temperature and precipitation in the Asian-Pacific Network region, 1955-2007. Int J Climatol 29:1906-1925

CMA (China Meteorological Administration) (2007) Yearbook of meteorological disasters in China (2007). China Meteorological Press, Beijing (in Chinese)

> Dai A, Trenberth KE, Qian T (2004) A global data set of Palmer Drought Severity Index for 1870-2002: relationship with soil moisture and effects of surface warming. J Hydrometeorol 5:1117-1130

Ding Y, Ren G (2008) Introduction to climate change science in China. China Meteorological Press, Beijing (in Chinese)

Easterling DR, Evens JL, Groisman PY, Karl TR, Kunkel KE, Ambenje P (2000) Observed variability and trends in extreme climate events: a brief review. Bull Am Meteorol Soc 81:417-425

Fan Y, Shi P, Zhou J, Ji M, Guan Y (2005) Research on changes in dust storms in China over the last 50 years. J Nat Disasters 14:22-28 (in Chinese)

> Frich P, Alexander LV, Della-Marta P, Gleason B, Haylock M, Klein Tank AMG, Peterson T (2002) Observed coherent changes in climatic extremes during the second half of the twentieth century. Clim Res 19:193-212

Gao W (1997) History of natural disasters in China. Seismological Press, Beijing (in Chinese)

> Gleason KL, Lawrimore JH, Levinson DH, Karl TR (2008) A revised U.S. climate extremes index. J Clim 21:2124-2137

Gong D, Han H (2004) Extreme climate events in northern China over the last 50 years. Acta Geogr Sin 59:230-238 (in Chinese)

Hansen J, Sato M, Glascoe J, Ruedy R (1998) A commonsense climate index: Is climate changing noticeably? Proc Natl Acad Sci USA 95:4113-4120

IPCC (Intergovernmental Panel on Climate Change) (2007) Climate change 2007: the physical science basis. Cambridge University Press, Cambridge

> Jiang Y, Luo Y, Zhao Z, Tao S (2010) Changes in wind speed over China during 1956-2004. Theor Appl Climatol 99: 421-430

Jones PD, Hulme M (1996) Calculating regional climatic time series for temperature and precipitation: methods and illustrations. Int J Climatol 16:361-377

Karl TR, Knight RW, Easterling DR, Quayle RE (1996) Indices of climate change for the United States. Bull Am Meteorol Soc 77:279-292

Kunkel KE, Pielke RA Jr, Changnon SA (1999) Temporal fluctuations in weather and climate extremes that cause economic and human health impacts: a review. Bull Am Meteorol Soc 80:1077-1098
Li Y, Chen L, Zhang S (2004) Statistical characteristics of tropical cyclones making landfall on China. J Trop Meteorol 20:14-23 (in Chinese)

Liu XF, Jiang Y, Ren GY, Wang Y (2009) Effect of urbanization and observation environment change on wind speed trend in Hebei Province, China. Plateau Meteorol 28: 433-439

Pielke RA Jr (2007) Mistreatment of the economic impacts of extreme events in the Stern review report on the economics of climate change. Glob Environ Change 17: 302-310

Qian W, Fu J, Zhang W, Lin X (2007) Changes in mean climate and extreme climate in China during the last 40 years. Adv Earth Sci 22:673-684 (in Chinese)

Ren GY, Chu ZY, Zhou YQ, Xu MZ (2005) Recent progresses in studies of regional temperature changes in China. Clim Environ Res 10:701-716 (in Chinese)

Ren GY, Zhou Y, Chu Z, Zhang A, Guo J, Liu X (2008) Urbanization effect on observed surface air temperature trend in North China. J Clim 21:1333-1348

Ren GY, Chen Y, Zou XK, Zhou YQ (2010) Definition and trend analysis of an integrated extreme climatic index. Clim Environ Res 15:354-364 (in Chinese)

Wang S, Wu R, Yang X, Zhai PM (2005) Climate change in China. In: Qin D, Ding Y, Su J (eds) Change in climate and environment of China (I). Science Press, Beijing, p 63-103 (in Chinese)

Wang X, Zhang Y (2006) Interdecadal change of the landing tropical cyclone tracks over China. J Dalian Marit Univ 32:41-45 (in Chinese)

Wang Y, Liu X, Ju X (2007) Differences between automatic and manual observation. J Appl Meteorol Sci 18:849-855 (in Chinese)

Wen KG, Ding YH (2008) China meteorological disasters. China Meteorological Press, Beijing (in Chinese)

Yan Z, Jones PD, Davies TD, Moberg A and others (2002) Trends of extreme temperatures in Europe and China based on daily observations. Clim Change 53:355-392

Zhai P, Pan X (2003) Trends in temperature extremes during 1951-1999 in China. Geophys Res Lett 30:1913 doi: 10.1029/2003Gl018004

Zhai P, Ren F, Zhang Q (1999) Detection of changing trend of extreme precipitation in China. Acta Meteorol Sin 57:208-216 (in Chinese)

Zhai P, Zhang X, Wan H, Pan X (2005) Trends in total precipitation and frequency of daily precipitation extremes over China. J Clim 18:1096-1108

Zhang L, Ren G (2003) Change in dust storm frequency and the climatic controls in northern China. Acta Meteorol Sin 61:744-750 (in Chinese)

Zhang Q, Zou X, Xiao F, Lu HQ (2006) GB/T20481-2006, grades of meteorological drought. China Standardization Press, Beijing (in Chinese)

Zhang X, Yang F (2004) RClimDex (1.0) user manual. Climate Research Branch, Environment Canada, Downsview, ON

Zhang X, Zwiers FW, Hegerl GC, Lambert FH and others (2007) Detection of human influence on twentiethcentury precipitation trends. Nature 448:461-466

Zhou Y, Ren G (2010) Variation characteristics of extreme temperature indices in mainland China during 19562008. Clim Environ Res 15:406-417 (in Chinese)

Zhou Z, Zhang G (2003) Strong dust storm events of northern China (1954-2002). Bull Chin Sci 48:1224-1228 (in Chinese)

Zou X, Ren G, Zhang Q (2010) Drought variations in China based on a compound index of meteorological drought. Clim Environ Res 15:371-378 (in Chinese) 